\title{
Equity of mobility in sustainable transportation
}

\author{
A. Savvides \\ University of Cyprus, Cyprus
}

\begin{abstract}
The paper examines issues of transport equity as they pertain to the efficiency of transport, its cost and people's mobility levels. It is also concerned with accessibility to transport for the greatest possible number of people, which together with transport equality leads to seeking fairness in mobility and accessibility levels across class, gender and disability. Moreover, the paper addresses aspects of transport equality with the goal of providing equal access to social and economic opportunity by looking into the provision of equal levels of access for all people to all places. Lastly, it delves on current concern in Cyprus about providing equal access to social and economic opportunity and it is centred on the issue of the "spatial mismatch hypothesis" - a term coined by Professor John F. Kain in 1968 (Housing segregation, Negro employment, and metropolitan decentralization) which refers to the disconnection between the locations of housing and jobs suitable for lower-income people and which is examined in this paper in the broader context of urban transport for sustainable urban development.
\end{abstract}

Keywords: equity, mobility, sustainable development, transportation planning, spatial mismatch.

\section{Introduction}

\subsection{Definitions of mobility and equity in a transportation context}

Transportation equity is concerned with the efficiency of transportation, its cost and people's mobility levels. It is also concerned with accessibility to transportation for the greatest possible number of people, which together with transportation equity leads to seeking fairness in mobility and accessibility levels across race, class, gender and disability. Ultimately, transportation equity has the goal to provide equal access to social and economic opportunity by providing 
equitable levels of access for all people to all places. Although these terms will be examined in a broad context, lessons learned may hopefully address concerns voiced in discussions regarding the implementation of expansion plans of the public transit network in major metropolitan areas of Cyprus.

\subsection{The spatial mismatch hypothesis}

Concern about providing equal access to social and economic opportunity has mostly centered on the issue of the "spatial mismatch hypothesis" [1], which refers to the disconnection between the locations of housing and jobs suitable for lower-income people. Those who most need entry-level jobs generally live in central cities, while entry-level jobs are mostly in suburban locations that are not easily accessible from central cities. This is certainly true of Cyprus as well.

\subsection{Social equity and social exclusion}

In other places, policymakers often take a broader view in the discussion of transportation, mobility and equity, as these themes pertain to the discussion of social inequity and social exclusion [2]. In that case, the effort is centered on combating social exclusion in a more wide-ranging approach than spatial mismatch, in that the main effort is to eradicate it by addressing communities that are isolated from or marginalized by general society. In that context - and according to the Social Exclusion Unit of the British Deputy Prime Minister public entities talk about "a shorthand term for what can occur when areas suffer from a combination of linked problems such as unemployment, poor skills, low incomes, poor housing, high crime, bad health and family breakdown [3].

\section{Public transit: a social service?}

Public transit has become first and foremost a social service [4]. Despite broad public support for mass transit in Cyprus and elsewhere, the automobile is the mode of choice for the vast majority of travelers. Rising personal income, the greater availability of automobiles and substantial public investment in highway systems, have all combined to reduce the general demand for public transit.

\subsection{Transit dependents and choice riders}

Many people without regular access to automobiles in the major metropolitan areas of Cyprus depend on public transit as their main mode of transportation. For these "transit dependents" the continued availability of public mass transit is vital for access to jobs, schooling, medical care and other necessities of life. Over the past few decades, the proportion of low-income transit riders has been rising with the influx of economic workers and immigrants, as more well-to-do local traveler have shifted to automobiles. Most of these transit users live in the innercity and many are members of disadvantaged groups, while "choice riders," those with regular access to private vehicles, are likely to be in the suburbs [4]. 


\subsection{Suburban transit demand}

Under public pressure to help address suburban transit demand, transit operators are expected to provide services that will be attractive to automobile users, especially single-occupant commuters who tend to have higher incomes and consequently more travel options than transit dependents. This increased emphasis on suburban commuter-oriented bus and rail services is progressively at odds with a growing inner-city ridership base of transit, consisting of people who lack adequate access to private transportation due to age, income and/or disability. This lack of sensitivity and attention to existing, yet inefficient, innercity bus services, especially in the capital region of Nicosia, raises questions about how public transit policies affect underserviced urban residents.

\subsection{Allocation of services}

The allocation of transit services between suburbanites and inner-city residents is not incidental, but rather it is connected to socioeconomic circumstances that have produced the observed polarization between suburbs and central cities. In this debate, while mainstream planning practices have been criticized for these patterns of uneven urban development, equity planning has shown itself to be centrally concerned with reducing such urban inequalities.

\subsection{Equity planning}

Krumholz [5] has defined equity planning as “ . . . an effort to provide more choices to those . . . residents who have few, if any choices" and he formulated his notion of equity planning to counteract what he perceived to be the inherent unfairness and exploitative nature of the urban development process, isolating the poor as a result of a lack of adequate public transportation. Related to this are policies of public investment in urban and intercity highways on the island that help empty central cities of middle-and-upper-income residents.

\section{Distribution of public investment}

Recently, architects and planners in Cyprus, influenced by the ideas of equity planning, have fought that which would further displace or disrupt low-income communities. Equity-minded planners are working to improve public transit service for those who depend on it for access to jobs, shopping, school and other services. In some cases, they have questioned proposed expensive rail transit projects in the capital region aiming to serve wealthier, suburban commuters at the expense of inner-city bus riders. They argue instead for lower bus fares and expanded bus service for transit dependent persons on the grounds that new fixed rail systems would not increase accessibility, but would draw resources away from suitable bus services [6]. 


\subsection{Population shifts}

It is also true of Cyprus as elsewhere that planners have tended to overlook the uneven distribution of public investment and public services in urban regions and their consequences for the lives of affected residents, as transit equity issues go well beyond disputes over particular projects. Questions are being raised about the provision of urban transportation services away from central cities and toward suburbs and outlying areas, a trend which has altered the historic ridership base for transit. Today's transit riders are, at least in Cyprus, poorer than the general population, with disproportionate numbers of elderly and immigrant and minority passengers.

\subsection{Transit subsidies}

Transit subsidy policies have generally not been consistent with these demographic shifts in urban transit use, but they have tended to support suburban and downtown commuter service transit networks, in an effort to attract more commuters out of their automobiles. However, the shift toward serving suburban travelers and the potential inattention to local bus service may diminish accessibility for inner-city residents, especially to employment opportunities, since typically half of all trips on public transit are work-related [7]. Although in line with broader statistics indicating that central cities contain only 30 percent of all workers, they still account for 70 percent of all transit use. In contrast, suburbs have half of all workers but generate only 30 percent of transit trips [8].

\subsection{Access to suburban employment}

Additionally, some proponents argue that commuter-oriented bus and rail transit systems are needed to provide transit-dependent inner-city residents better access to suburban employment. While opportunities exist to better link central cities and suburbs with public transit, as is the case with the major metropolitan areas in Cyprus, the role of these "reverse commutes" in travel should be considered. For low-income workers this may result in fairly long commutes and they must balance the time and expense of commuting against the wages from a potential job in the suburbs. But while the number of new jobs created in the suburbs has been increasing there is still a substantial number of job opportunities still located in the inner-city [9]. The challenge arises in that current and proposed transit networks work well at connecting suburban residential areas the innercity; they are less effective, however, in connecting inner-city residents to dispersed suburban employment sites, especially when considering timeconsuming transfers.

\subsection{Reverse commute access programs}

In these reverse commutes, the employment access advantage of automobiles helps to explain why many living in poor households still chose to own a car and drive to work [10]. It also explains why so many reverse-commute transit 
programs elsewhere in the world lose riders to automobiles when low-wage reverse commuters buy cars $[11,12]$. Reverse commute transit programs can play a role in increasing job access for low-income central city residents. Also, improving the quality of heavily used local transit service and reducing fares for short and off-peak trips would clearly do more to connect workers without cars to urban and suburban employment opportunities [13]. Failure to better integrate transit ridership patterns and subsidy policies, may have both a social and a spatial consequence that can reinforce patterns of segregation. In such a case, poor public transit service in areas with high proportions of transit dependents would exacerbate problems of social and economic isolation and it would decrease choices for those who already have limited transportation options.

\section{Transportation and mobility inequities}

Policies concerning issues of mobility can have a direct effect on low-income, minority communities by making it difficult for them to access transportation to various places, as indeed, transportation policies emphasizing road construction have led to a dependency on automobiles and a rise in transportation costs. In the United States for example, 80 cents of every dollar spent on federal surface transportation programs is earmarked for highways, while only 20 cents are earmarked for public transit [14]. Consequently, policies that restrict allocation of public funds to public transit contribute to increasing household transportation expenses, particularly for low-income families, a point that Cypriot planners would do well to keep at the back of their minds.

\subsection{Impact of transportation costs}

In fact, data from consumer expenditure surveys suggest that low-income households devote a greater proportion of their income to transportation-related expenses regardless of whether they use public transportation or own a car, with low-income workers who use a vehicle to commute spending $7 \%$ more of their income on transportation costs compared with those using public transit [15]. Moreover, in some metropolitan areas, households spend as much for transportation as they do for housing, with the lowest income segment of the population may end up spending more than a third of their household budget on transportation, compared to an eighth in the highest income segment [16].

\subsection{Transportation expenditures}

Another measure of the impact of transportation costs on low-income households is the rate of increase in transportation expenditures, wherein research suggests not only these low-income families are spending more of their incomes on transportation, but also that transportation costs are increasing at a faster rate for these households. It follows then that as public transit services diminish, a household's auto dependency increases. These trends indicate that household transportation costs are increasing over time, meaning that households have less to spend on housing, food, health care, insurance, education and other needs. 


\subsection{Debt incursion}

Yet other evidence suggests that the debt incurred by families related to car ownership makes buying a home more difficult [16]. In addition, research indicates that inefficient land use patterns and low-density, noncontiguous development - that makes public transit an infeasible option for many commuters - contribute to negative impacts on energy consumption, air quality and public health [17]. Moreover, a major factor contributing to these rising costs is probably the sprawling development patterns observed in metropolitan areas, which translate to longer travel distances and more auto dependency.

\section{Indirect effects of transportation policies}

One of the central indirect effects of inefficient mobility is the reinforcement of residential segregation, especially in urban areas, such as the historic though neglected inner-city cores of the major metropolitan areas of Cyprus, which are a product of both land use and transportation investment decisions [18]. To the contrary, investments in automobile related infrastructure, in combination with housing and lending policies leading to urban sprawl, have had a significant impact in defining urban form and income inequalities elsewhere [19], as well as in Cyprus, while inequitable or inefficient land use patterns, such as those resulting in residential segregation, have oftentimes been reinforced by policies, such as transportation investment decisions, that were established several decades ago and have influenced disadvantaged residents' mobility and their access to economic opportunities, housing and even education [20].

\subsection{Spatial mismatch and access to employment}

Moreover, the perceived spatial mismatch between the residential location of low-income, urban households and the location of low-skill jobs receives significant attention and it has been observed in Cyprus as well that while managerial and information processing service-oriented jobs have tended to remain in downtown areas, entry-level, low-skill jobs oftentimes offered by employers located in industrial zones have been moving to the urban fringe and beyond, where the average distance between a commuter's home and potential employment location has been increasing over time [21]. In addition, despite the trend for businesses to relocate in suburban zones, a large proportion of metropolitan employment remains in downtowns underlying the observed spatial mismatch [22]. As a result, as this distance increases, low-skilled workers with few transportation options are unable to travel to these new, dispersed locations.

\subsection{Job locations}

If one accepts the fact that when job locations are concentrated, commute times and distances are shorter than when jobs are located in dispersed locations, it follows that commuting to jobs in dispersed locations is inefficient, as transitdependent populations have limited travel mode options. In addition, because it 
is difficult for public transportation to serve dispersed suburban locations from the central city, workers who have or would like to take a job in the suburbs and are transit-dependent are put at a distinct disadvantage [23]. Without reliable transportation options, transit-dependent workers can easily be excluded from employment opportunities, as urban public transit systems, which operate most efficiently in concentrated, densely developed urban areas, are oriented toward downtowns and tend to under-serve dispersed origins and destinations [1].

\subsection{The private automobile option}

On the other hand others argue - and their arguments find resonance in planning circles in Cyprus - that public transit is not a viable alternative to the personal automobile option due to the geographic imbalance between housing and job locations [13, 24]. They even suggest that increased automobile ownership rates may have beneficial impacts on low-income workers and their families [25-27], as automobiles are said to improve job search activities and to assist in job retention, especially in cases when public transit is unavailable [13]. They also argue that automobiles provide flexibility beyond work-related trips, so that individuals can meet other daily needs related to child care, education, shopping, health care, etc. Consequently, they argue, the role of cars should be a consideration in transportation mobility strategies for low-income, immigrant and minority segments of society, the challenge in this case being the formulation of policies that increase alternative transportation access in cases where conventional modes of mobility are not possible.

\section{The effects of displacement and gentrification on access to housing}

Displacement and gentrification are commonly characterized as transformations of neighborhood conditions that encompass physical, economic and demographic dimensions and can be defined as "the processes by which higher income households displace lower income residents of a neighborhood, changing the essential character and flavor of that neighborhood [28].”

\subsection{Access to housing}

Problematic access to housing because of transportation projects are examples of the negative impacts of displacement and gentrification that have been inflicted on low-income neighborhoods, indicating that residential location and housing are directly related to the need for equitable and efficient transportation systems, especially for persons with limited mobility. Moreover, the affected individuals have fewer options in seeking alternative housing and may end up living farther away from their jobs and social networks. This is especially burdensome if their transportation options are limited indicating that an individual's residential location is crucial with regards to issues of affordability of public transportation and access to social services and education [29]. 


\subsection{Increases to property values}

This coupling of displacement and gentrification and their effect on access to housing may occur for a number of reasons, including increased desirability of an area due to a transportation investment such as extension of a bus or train line, new or improved service or addition of a highway ramp or exit. In this context, gentrification has been portrayed in terms of residential location patterns, such as flows of middle-income households back to the city and it manifests itself through reinvestment and rehabilitation of previously degraded neighborhoods, improving the physical condition and appearance of both residential and commercial properties. Increases in property values are then capitalized in rent increases, which in turn push households that are less able to afford the higher cost of living to other neighborhoods or to undesirable housing arrangements [30]. In particular, some argue that certain anti-sprawl land use policies that direct housing development away from the urban fringe reduce housing affordability and limit housing choice for low-income households [31, 32].

\section{Concluding thoughts}

Equity in issues of mobility needs to addresses a distribution of impacts and whether they are considered fair and appropriate, as mobility considerations in planning decisions often have significant equity impacts. Even though a particular decision may seem equitable evaluated one way, it may be inequitable evaluated another, especially since many people fall into multiple categories and change status over time or since new equity issues emerge over time, reflecting changing needs, values and understanding of impacts. It is not always feasible to evaluate all possible permutations of impacts and perspectives of affected groups, but it is always prudent to try to encourage public involvement and to recognize the full spectrum of possible issues so as to select those most appropriate for a particular situation.

\subsection{Mobility and equity considerations}

Mobility and equity considerations can be incorporated in transportation planning and funding, land use planning, the provision of transportation services and just about any other transportation decision-making aspect [33]. In doing so successfully, some general guidelines may include the following:

- The consideration of a variety of perspectives and impacts when evaluating equity.

- $\quad$ The allocation of transportation resources as equitably as possible.

- The expectation that basic mobility and access needs are met.

- The prioritization of facilities and services that favor basic transport.

- The securitization of an adequate level of service consideration of disadvantaged groups.

- The provision of special discounts and exemptions to the disadvantaged. 
In considering all of the above, the involvement of all stakeholders in planning to help identify equity concerns and priorities, to reduce conflicts and delays and to reflect a community's needs, values, concerns and priorities.

\subsection{Quality of life issues}

Transportation is also a basic ingredient for quality of life indicators such as health and safety, education and employment, economic development and access to municipal services, residential mobility and environmental quality. Transportation investments, enhancements and financial resources, if used properly, can bring new life and revitalization to much needed urban areas [34].

\subsection{Discrimination possibilities}

Class dynamics may isolate many low-income, inner-city residents from expanding suburban job centers. Transportation funds that have fueled suburban highway construction and job sprawl, have also isolated residents from their institutions and businesses, contributed to urban sprawl and subjected residents to elevated risks. Sustainable and equitable transportation policies, being a key ingredient in any plan to build economically viable communities, have a major responsibility to ensure that they do not discriminate against or adversely impact transit dependant segments of the population.

\subsection{Subsidization concerns}

Considering ridership demographics and potential policy responses is a function of diverging spatial frameworks that shape demand for transit services on one hand and guide public subsidization on the other. However, while transit demand tends to concentrate in high-density, low-income areas, subsidies oftentimes favor lower-density, higher income areas. And since the majority of transitdependent riders are poor and members of minority groups, the ongoing shifts in ridership patterns and the failure of transit authorities to respond to the growing disparity in service between transit-dependent and discretionary riders, becomes a progressively increasing cause for concern that should be addressed.

\subsection{An important step}

The previous statements raise a number of normative questions regarding the value of public transit: how is fairness defined in the context of public transit? An important step in beginning to address these issues is to try and define the frame of reference for judging equity and fairness. Shifting the focus onto the distribution of benefits for classes of transit users would alter the perspective over transit equity by challenging the fairness of public transit service provision. If then public transit is also seen as a social service for the disadvantaged, planners will be well on their way to being not only well trained and informed, but also to being fair-minded practitioners. 


\section{References}

[1] Kain, J. F. Housing segregation, Negro employment, and metropolitan decentralization. Quarterly Journal of Economics, 82, 175-197, 1968.

[2] Sinclair, S. P. and Sinclair, F. Access all areas? An assessment of social inclusion measures in Scottish local transport strategies. Center for Research into Socially Inclusive Services, Edinburgh College of Art/ Herriot-Watt University, 2001.

[3] Church, A., Frost, M. and Sullivan, K. Transport and social exclusion in London. Transport Policy, 7(3), 195-205, 2000.

[4] Garrett, M. and Taylor, B. Reconsidering Social Equity in Public Transit, Berkeley Planning Journal, 13(1), 6-27, 1999.

[5] Krumholz, N. A Retrospective View of Equity Planning: Cleveland 19691979. Journal of the American Planning Association, 48(2:1), 63-74, 1982.

[6] Krumholz, N. and Forester, J. Making Equity Planning Work. Philadelphia, Temple University Press, 1990.

[7] Hu, P. S. and Young, J. 1990 NP TS Databook: Nationwide Personal Transportation Survey, Vol. 1. Federal Transit Administration, Washington, D.C., 1993.

[8] Pisarski, A. E. Commuting in America 11: The Second National Report on Commuting Patterns and Trends. Eno Transportation Foundation, Inc., Landstowne, VA., 1996.

[9] Shen, Q. Location Characteristics of Inner-city Neighborhoods and Employment Accessibility of Low-wage Workers. Environment and Planning B: Planning and Design, 25(3), 345-65, 1998.

[10] Pisarski, A. Travel Behavior Issues in the 90s. Office of Highway Information Management, Federal Highway Administration, Washington D.C., 1992.

[11] Ong, P. Work and Automobile Ownership Among Welfare Recipients. Social Work Research, 20(4), 1996.

[12] Rosenbloom, S. Reverse Commute Transportation: Emerging Provider Roles. U.S. Department of Transportation, University and Training Program, Washington, D.C., 1992.

[13] Wachs, M. and Taylor, B. D. Can Transportation Strategies Help Meet the Welfare Challenge? Journal of the American Planning Association, 64(1), 15-21, 1998.

[14] Puentes, R., and Prince, R. Fueling transportation finance: A primer on the gas tax. Washington, D.C.: Brookings Institution, 2003.

[15] U.S. Department of Transportation. BTS Issue Brief (No.1), Bureau of Transportation Statistics. Washington, D.C., 2003.

[16] Surface Transportation Policy Project and Center for Neighborhood Technology. Driven to spend: The impact of sprawl on household transportation expenses. Washington, D.C., 2000.

[17] Environmental Justice Resource Center. Sprawl, Atlanta: Social equity dimensions of uneven growth and development. Atlanta: Clark-Atlanta University, 1999. 
[18] Jackson, K. T. Crabgrass frontier. New York: Oxford University Press, 1985.

[19] Downs, A. Suburban housing: A program for expanded opportunities. Real Estate Review, 1(1), 4-10, 1971.

[20] Orfield, G. and Eaton, S. E. Dismantling desegregation: The quiet reversal of Board v. Board of Education. New Press, 1996.

[21] Holzer, H. J. The spatial mismatch hypothesis: What has the evidence Shown? Urban Studies, 28, 105-122, 1991.

[22] Ihlanfeldt, K. R. and Sjoquist, D. L. The spatial mismatch hypothesis: A review of recent studies and their implications for welfare reform. Housing Policy Debate 9(4), 849-892, 1998.

[23] U.S. Census 2000 (retrieved from:http://www.census.gov/population/ www/socdemo/journey.html and http://www.census.gov/populatin/www/ cen2000/commuting.html).

[24] Ong, P. and Blumenberg, E. Job access, commute and travel burden among welfare recipients. Urban Studies, 35(1), 77-93, 1998.

[25] Ong, P. Work and car ownership among welfare recipients. Social Work Research, 2(4), 255-262, 1996.

[26] Blumenberg, E. On the way to work: Welfare recipients and barriers to employment. Economic Development Quarterly, 16(4), 314-325, 2002.

[27] Raphael, S. and Rice, L. Car ownership, employment, and earnings. Journal of Urban Economics, 52, 109-130, 2002.

[28] Kennedy, M. and Leonard, P. Dealing with neighborhood change: A primer on gentrification and policy choices. Retrieved June 2003 from http://www.

brookings.edu/dybodocroot/es/urban/gentrification/gentrification.pdf.

Washington, D.C.: The Brookings Institution and Oakland, CA: Policy Link, 2001.

[29] Lee, B. L. Civil Rights and legal remedies: A plan of action. In R. D. Bullard \& G. S. Johnson (Eds.), Just transportation: Dismantling race \& class barriers to mobility. Gabriola Island, BC: New Society Publishers, 1997.

[30] Sanchez, T. W. Equity analysis of personal transportation system benefits. Journal of Urban Affairs, 20(1), 69-86, 1998.

[31] Hodge, D. Inner city revitalization as a challenge to diversity? Seattle. In S. B. Laska and D. Spain (Eds.), Back to the City: Issues in neighborhood renovation (pp. 187-203). New York: Pergamon Press, 1980.

[32] Laska, S. B. and Spain, D. (1980). Back to the city: Issues in neighborhood renovation. New York: Pergamon Press, 1980.

[33] Litman, T. Evaluating Transportation Equity. World Transport Policy \& Practice (http://ecoplan.org/wtpp/wt_index.htm), Volume 8, No. 2, pp. 50-65, 2002.

[34] Bullard, R. D. Addressing Urban Transportation Equity in the United States, Fordham Urban Law Journal, 31(5:2), 2003. 